\title{
AOR
}

Selected Papers of \#AolR2020:

The 21st Annual Conference of the

Association of Internet Researchers

Virtual Event / 27-31 October 2020

\section{WHOSE SHAREDPLANS? SCRIPTS, COLLABORATION, AND FEMINIST AI RESEARCH}

\author{
Rachel Bergmann \\ Microsoft Research
}

\section{Introduction}

Critical and feminist histories of computing have begun to explore the way race, class, gender, culture, and other social factors have shaped the development of computing technologies, and how these technologies in turn help construct and enforce cultural and social norms. Recent histories (Hicks 2017; Rankin 2018) frame the history of computing as deeply embedded in a web of social, political, and cultural forces which have shaped the labour forces, forms of access, and imaginaries surrounding computing technologies. This paper aims to offer a supplement to these critical histories and build on the growing body of "critical Al studies" literature that considers particular artificial intelligence (Al) techniques and technologies in terms of their sociocultural contexts and implications. Approaching Al historically offers a way to consider algorithms and AI technologies beyond their technical specifications, instead analyzing them as complex sociotechnical assemblages shaped by material, geographic, political, and social forces.

\section{Feminist Al Protocol}

Using a technofeminist framework (Wajcman 2004), I examine a network of women in Al research who together expanded the range of methodologies and disciplines usually included in Al in the 1980s and 1990s. Barbara Grosz and Candace Sidner, two of these women, developed a concept called SharedPlans (Grosz \& Sidner 1986) that challenged more masculine approaches to dialogue systems. Borrowing from Michelle Murphy's (2012) concept of protocol feminism, I argue these women had a feminist Al protocol, a collection of methods and practices rooted in community, interdisciplinarity, and care.

I analyze these women in the history of Al research as complex, politically imperfect characters. I outline the sets of practices and techniques they used in their research objectives, scientific method, areas of specialization, and involvement in academic service. I consider their significant contributions to both Al research and creating spaces for women in computer science. I also consider the ways their social contexts limited the extent to which their protocols offered more radical epistemological imaginings of a feminist approach to Al. 


\section{Method}

I draw on scholarship in critical algorithm studies and feminist STS, which has provided frameworks to uncover and challenge the assumptions and values which have been foundational to scientific and technological research (e.g., Haraway 1990).

Using humanistic and documentary methods, I analyze published and unpublished documents, interviews, conference proceedings, white papers, and departmental reports. I analyze the publications of Barbara Grosz and Candace Sidner, the two authors of SharedPlans, and situate their work within broader intellectual currents at the time within $\mathrm{Al}$ and in other disciplines. I consider how their theoretical approach in this period resonated with contemporaneous work produced in feminist theory and STS. I support this analysis with biographical interviews with Barbara Grosz and other Al researchers, conducted from summer 2019 through fall 2020.

\section{Findings \& Implications}

I outline an assemblage of techniques, values, and practices that illustrate a feminist Al protocol rooted in community, interdisciplinarity, and care. SharedPlans helped create the infrastructure for a computer dialogue system that could go "off-script" and it was grounded in a philosophy of language as action.

Grosz and Sidner approached their research philosophically, using frameworks from philosophy and speech act theory (Searle 1969, 1980) to frame dialogue as fundamentally collaborative. SharedPlans helped deconstruct certain notions of individualism and research methods that focused too narrowly on normative scripts, tasks, and utterances (Schank \& Abelson 1977). Instead, their research methods were grounded in the diverse goals and desires of real users.

Grosz advocated for the metaphor of a team or partnership to describe the relationship humans and Al systems ought to have- and the systems computer scientists ought to design. Outside research, many of these women spent their academic careers advocating for feminist issues in the computer science community (Grosz 1991; Sidner 1982). In many ways, their approaches to Al align with feminist and critical STS work circulating simultaneously (Adam 1993, 1995; Akrich 1992; Woolgar 1990).

In other ways, this network of researchers enacted their Al protocol from within the particular set of cultural and epistemological parameters of their computer science departments. SharedPlans built collaborative capability into existing work on intelligent agents, but this model was contained within limits of rational agency and self-interest. These parameters limited how radical the epistemological interventions of Grosz and her collaborators could have been.

\section{Conclusion}

Paying attention to the limits of SharedPlans helps shed light on particular epistemic norms within the history of computing technologies and clarifies the kinds of commitments necessary for creating feminist technologies in solidarity with other movements. To conclude, I consider Feminist Internet's "Feminist Alexa" chatbot to imagine a feminist Al research agenda rooted in intersectionality, anti-imperialism, and 
anti-capitalism. The project's design decisions emphasize the way claims to truth and knowledge are historically contingent, socially and culturally mediated, and shaped by prior experiences. There remains an urgent need to reflect on how to build feminist Al technologies that make room for and include many different standpoints.

\section{References}

Adam, Alison. "A Feminist Critique of Artificial Intelligence." European Journal of Women's Studies 2, no. 3 (August 1995): 355-77. https://doi.org/ 10.1177/135050689500200305.

. "Gendered Knowledge - Epistemology and Artificial Intelligence." Al \& SOCIETY 7, no. 4 (December 1, 1993): 311-22. https://doi.org/10.1007/BF01891414.

Akrich, Madeleine. "The De-Scription of Technical Objects." In Shaping Technology/ Building Society. Studies in Sociotechnical Change, edited by Wiebe E. Bijker and John Law, 205-24. Cambridge, Massachusetts: MIT Press, 1992. https://halshs.archivesouvertes.fr/halshs-00081744.

Feminist Internet. "Designing a Feminist Alexa: An Experiment in Feminist Conversation Design." UAL creative computing institute. Accessed April 17, 2019. https:// drive.google.com/file/d/1vIrIT8dIA9muhvd-XfCCCCUQCujRhMOO/view? usp $=$ drive_open\&usp $=$ embed_facebook

Grosz, Barbara J. "Report on Women in the Sciences at Harvard. Part I: Junior Faculty and Graduate Students." Faculty of Arts and Science Committee on the Status of Women. Cambridge, Massachusetts: Harvard University, February 13, 1991, 1-36.

Grosz, Barbara J. and Candace L. Sidner. "Attention, intentions, and the structure of discourse." Computational Linguistics 12, no 3 (1986): 175-204.

Haraway, Donna. Simians, Cyborgs, and Women: The Reinvention of Nature. 1 edition. New York: Routledge, 1990.

Hicks, Mar. Programmed Inequality: How Britain Discarded Women Technologists and Lost Its Edge in Computing. Cambridge, MA: MIT Press, 2017.

Murphy, Michelle. Seizing the Means of Reproduction: Entanglements of Feminism, Health, and Technoscience. Duke University Press, 2012.

Rankin, Joy Lisi. A People's History of Computing in the United States. Cambridge, Massachusetts: Harvard University Press, 2018.

Schank, Roger C., and Robert P. Abelson. Scripts, Plans, Goals, and Understanding: An Inquiry Into Human Knowledge Structures. New York: Psychology Press, 1977.

Searle, John R. "Minds, Brains, and Programs." Behavioral and Brain Sciences 3, no. 3 (September 1980): 417-24. https://doi.org/10.1017/S0140525X00005756. 
Searle, John. 1969. Speech Acts: An Essay in the Philosophy of Language. Cambridge University Press, Cambridge, England.

Sidner, Candace. "On Being a Woman at MIT: Or, How to Miss the Stumbling Blocks in Graduate Education." Association for Women in Mathematics Newsletter, February 1982, 13-17.

Wajcman, Judy. TechnoFeminism. Cambridge; Malden, MA: Polity, 2004.

Woolgar, Steve. "Configuring The User: The Case of Usability Trials." The Sociological Review 38 (1990): 58-99. https://doi.org/10.1111/j.1467-954X.1990.tb03349.x. 